\title{
Patterns of sulfur isotope fractionation during microbial sulfate reduction
}

\section{Citation}

Bradley, A.S., W.D. Leavitt, M. Schmidt, A.H. Knoll, P.R. Girguis, D.T. Johnston. 2015. Patterns of sulfur isotope fractionation by sulfate reducing bacteria. Geobiology. DOI: 10.1111/gbi.12149.

\section{Published Version}

doi:10.1111/gbi.12149

\section{Permanent link}

http://nrs.harvard.edu/urn-3:HUL.InstRepos:30367425

\section{Terms of Use}

This article was downloaded from Harvard University's DASH repository, and is made available under the terms and conditions applicable to Open Access Policy Articles, as set forth at http:// nrs.harvard.edu/urn-3:HUL.InstRepos:dash.current.terms-of-use\#OAP

\section{Share Your Story}

The Harvard community has made this article openly available.

Please share how this access benefits you. Submit a story.

\section{Accessibility}




\section{PATTERNS OF SULFUR ISOTOPE FRACTIONATION BY SULFATE REDUCING BACTERIA}

$4 \quad$ Alexander S. Bradley ${ }^{1, *,}$, William D. Leavitt ${ }^{1,2, \dagger}$, Marian Schmidt ${ }^{2,3}$, Andrew H. Knoll ${ }^{2,4}$, 5 Peter R. Girguis ${ }^{4}$, and David T. Johnston ${ }^{2}$

${ }^{1}$ Department of Earth and Planetary Sciences, Washington University in St. Louis, 1 Brookings Drive, St. Louis MO, 63130

$9{ }^{2}$ Department of Earth and Planetary Sciences, Harvard University, 20 Oxford Street, Cambridge MA 02138

$11{ }^{3}$ Department of Ecology \& Evolutionary Biology, University of Michigan, 830 North University, Ann Arbor, MI 48109

23 Running title: Ecophysiology of SRB S-isotope fractionation 
ABSTRACT

Studies of microbial sulfate reduction have suggested that the magnitude of sulfur isotope fractionation varies with sulfate concentration. Small apparent sulfur isotope fractionations preserved in Archean rocks have been interpreted as suggesting Archaean sulfate concentrations of less than $200 \mu \mathrm{M}$, while later larger fractionations have been interpreted to require higher sulfate concentrations. In this work, we demonstrate that isotope fractionation can sometimes vary with sulfate concentrations over a large range of concentrations, but that this relationship

33 depends on the organism being studied. Two sulfate reducing bacteria grown in continuous

34 culture between 0.1 and $6 \mathrm{mM}$ sulfate showed markedly different relationships between sulfate 35 concentration and isotope fractionation. Desulfovibrio vulgaris str. Hildenborough cultures 36 showed a large and relatively constant isotope fractionation $\left({ }^{34} \varepsilon_{\text {SO4-H2S }} \cong 25 \%\right.$ o) over the 37 experimental range of sulfate concentrations. Over the same concentration range, fractionation 38 by Desulfovibrio alaskensis strain G20 strongly correlated with sulfate. Both data sets can be 39 modeled as Michaelis-Menten (MM) type relationships but with very different MM constants, 40 suggesting that the fractionations imposed by these organisms respond in dramatically different 41 ways to sulfate concentrations.

42 These data reveal complexity in the sulfate concentration-fractionation relationship. 43 Sulfur isotope fractionation during sulfate reduction relates to environmental sulfate 44 concentrations but also to strain-specific physiological parameters such as the affinity of sulfate45 reducing microorganisms for sulfate and electron donors. Previous studies have suggested that 46 the relationship between sulfate concentration and isotope fractionation is best fit with a MM fit. 47 suggested We present a simple model, grounded in the physiology of sulfate reduction, in which 48 the ratio of MM relationships for sulfate and electron donor uptake produces the relationships 49 seen in experimental studies: a MM relationship with sulfate concentration, and a hyperbolic 50 relationship with growth rate.

51 Since both environmental and biological factors influence the fractionation recorded in 52 geological samples, understanding their relationship is critical to interpreting the sulfur isotope 53 record. As the acquisition machinery for sulfate and electron acquisition has been subject to 54 selective pressure over Earth history, its evolution may complicate efforts to uniquely reconstruct 55 ambient sulfate concentrations from a single sulfur isotopic composition. 
57 Keywords: co-limitation and threshold effects; Michaelis-Menten; marine sulfate concentration;

58 Archean seawater

59

60

61 
Evolution of the marine sulfate reservoir is a key parameter in modeling Earth's surface oxidation state through time (Berner and Canfield, 1989; Canfield, 2004). Today, seawater sulfate represents an oxidant reservoir ten times the size of atmospheric $\mathrm{O}_{2}$ (Hayes and Waldbauer, 2006). One of the most powerful tools for understanding the evolution of the sulfate reservoir, and by proxy the surface sulfur cycle, is the ratio of stable sulfur isotopes in sulfur-bearing minerals found in marine sedimentary rocks. Marine sulfate concentrations are linked to geological isotope records largely via microbial metabolism, most notably by microbial sulfate reduction (MSR), a metabolic process that couples organic carbon or hydrogen oxidation to sulfate reduction. Details of isotopic records permit the quantification of seawater sulfate through Earth history, but such inferences are predicated on a fundamental understanding of the broad suite of factors that

74 influence the fractionation of sulfur isotopes during MSR.

MSR can yield a large mass-dependent fractionation between sulfate and sulfide (Chambers et al., 1975; Harrison and Thode, 1958; Leavitt et al., 2013; Sim et al., 2011c); the product sulfide is depleted in heavy isotopes, leaving the residual sulfate enriched. Both environmental and physiological factors contribute to the expressed fractionation. For example, Habicht et al. (2002) presented data suggesting that ${ }^{34} \mathrm{~S} /{ }^{32} \mathrm{~S}$ fractionations greater than 5\%o are expressed only when ambient sulfate concentration exceeds $200 \mu \mathrm{M}-$

81 approximately one percent of the modern seawater sulfate concentration. This 82 concentration threshold is similar in magnitude to the sulfate half-saturation 83 concentrations $\left(K_{S}\right)$ associated with growth kinetics of some MSR strains (Pallud and Van 84 Cappellen, 2006; Tarpgaard et al., 2011). When paired with Precambrian sedimentary 85 sulfur isotope record, this fractionation threshold value was taken to imply an increase in 86 seawater sulfate concentrations near the Archean - Proterozoic boundary, where a 87 dramatic expansion of S-isotope fractionation is preserved (Habicht et al., 2002). This, in 88 turn, suggests a strong physiological control on the geological isotope record (Habicht et al., 89 2002; Habicht et al., 2005; Szabo et al., 1950) and implies that as microbial physiologies are 90 better understood, more refined geological storylines are possible. 
Microbial physiology provides the context for mechanistically evaluating how low sulfate

92 concentrations limit sulfur isotope fractionation. Extensive work on the sulfate uptake half-

93 saturation constant $\left(K_{\mathrm{s}}\right)$ demonstrates a range of uptake capacities in natural communities and

94 pure cultures alike (see compilations in (Pallud and Van Cappellen, 2006; Tarpgaard et al.,

95 2011). For instance, it was originally intuited that microbes that evolved in and adapted to

96 lacustrine environments with low ambient sulfate concentrations will have low $K_{s}$ values, with

97 the opposite posited for marine strains (Bak and Pfennig, 1991; Holmer and Storkholm, 2001).

98 However, in natural samples, measured $K_{\mathrm{s}}$ values show no clear relationship with salinity;

99 freshwater and marine sediments have apparently similar ranges of $K_{\mathrm{s}}$ (see review in Tarpgaard

100 et al. (2011)). That said, low $K_{\mathrm{s}}$ values have been observed more frequently in freshwater

101 cultures than in marine cultures (Tarpgaard et al., 2011). Further, Tarpgaard et al. (2011)

102 demonstrate that individual microbial strains within a community can have different apparent $K_{\mathrm{s}}$,

103 values for sulfate, lessening the validity of using the realized $K_{\mathrm{s}}$ as a proxy for the all members

104 of a given environment. This is also consistent with genomic analyses (Hauser et al., 2011;

105 Heidelberg et al., 2004), which suggest that individual microbial strains may carry multiple

106 sulfate transporters, possibly of varying sulfate $K_{\mathrm{s}}$ and $V_{\max }$ (maximal transport rate). Such

107 complexity suggests that a single measure of cellular $K_{\mathrm{s}}$ is an imperfect guide to the

108 concentration-dependence of fractionation. As such, the relationship between sulfate

109 concentration/activity, transport, and isotope fractionation is likely more complex than a simple

110 and universal sulfate concentration threshold value and related step-function change in sulfur

111 isotope fractionation.

112 It should also be noted that sulfate transporters enable sulfate-reducing microorganisms

113 to compete for sulfate as a function of both the cellular half-saturation constant, $K_{\mathrm{s}}$, and of the

114 maximum rate of cellular sulfate uptake, $V_{\max }$. It is important to appreciate that $V_{\max }$ itself is also

115 a function of the number and characteristics of sulfate ion transporters in the cell membrane

116 (Aksnes and Egge, 1991). Much work suggests that the appropriate parameter to describe the

117 cellular uptake efficiency for any ion - including sulfate - is the affinity parameter $A_{\mathrm{s}}$, which is

$118 V_{\max } / K_{\mathrm{s}}$ (Aksnes and Egge, 1991; Button, 1985; Healey, 1980; Smith et al., 2009). This term

119 captures the influence of both the maximal rate of transport and the half-saturation constant. As

120 strains with a higher $A_{\mathrm{s}}$ are able to import sulfate more efficiently into the cell, the opportunity

121 for isotope fractionation should increase; at low transport velocities (i.e. sulfate import rates), 
122 transported sulfate is likely to be quantitatively reduced to sulfide, which due to mass balance 123 would minimize isotopic fractionation.

124 In this study we report results from two sets of continuous-culture experiments, 125 each employing an axenic strain of sulfate-reducing bacteria. We examine pure strains 126 rather than enrichment cultures or diverse sedimentary communities in order to avoid 127 complexities introduced by multiple competing strains, each with potentially different 128 sulfate affinities and transport kinetics. In each set of experiments, the bacterial population 129 was cultivated at steady state under a range of different sulfate concentrations (0.1 to 6 $130 \mathrm{mM}$ ) in order to assay the relationship between sulfate concentration and isotope 131 fractionation. The freshwater (Desulfovibrio vulgaris str. Hildenborough) and marine

132 (Desulfovibrio alaskensis str. G20) strains selected are among the most well studied sulfate 133 reducers (Hansen, 1994; Pereira et al., 2011; Wall et al., 1993). Each strain has a fully 134 sequenced genome (Hauser et al., 2011; Heidelberg et al., 2004), is genetically tractable, 135 and is biochemically well-characterized (Grein et al., 2013; Venceslau et al., 2014), 136 providing a wide range of tools for follow-up investigations.

137 To date, previous physiological work has reported one sulfate $K_{\mathrm{S}}$ for $D$. vulgaris at $1380.032 \mathrm{mM}$ (Ingvorsen and Jørgensen, 1984). The genome of $D$. vulgaris 139 (http://www.ncbi.nlm.nih.gov) further contains three annotated sulfate transport proteins. 140 In contrast, D. alaskensis has no reported $K_{s}$; however, closely related strains have values 141 ranging from $0.005 \mathrm{mM}$ to greater than $0.250 \mathrm{mM}$ (Dalsgaard and Bak, 1994; Fukui and 142 Takii, 1994; Okabe et al., 1992). The D. alaskensis genome contains at least 10 sulfate 143 transporters; unknown transport proteins are also present and may increase this estimate. 144 Such redundancy is consistent with the notion that a range of sulfate affinities can be 145 exhibited in a single strain or environment (Tarpgaard et al., 2011). Here we present the 146 experimental design and results, consider potential physiological and environmental 147 factors that can explain the observed differences, and discuss the ramifications of these 148 data on interpretations of the geological sulfur isotope record.

\section{MATERIALS AND METHODS SUMMARY}


151 Each strain (D. alaskensis and D. vulgaris) was grown in stirred continuous culture 152 vessels held at room temperature $\left(25^{\circ} \mathrm{C}\right)$ for roughly 40 days. We employed a continuous flow 153 bioreactor to avoid the complexities of closed-system Rayleigh distillation effects incurred 154 during growth in batch culture (Leavitt et al., 2013). In continuous culture at steady state, 155 concentration of the limiting substrate (in this case, lactate) remains invariant and is a function of 156 dilution rate; the growth rate $\left(\square \square\right.$ day $\left.^{-1}\right)$ is also constant and equal to the dilution rate $157\left(D \square\right.$ day $\left.^{-1}\right)$. This design allowed us to match $D$. vulgaris and $D$. alaskensis growth rates at $1580.037 \pm 0.003$ and $0.034 \pm 0.001\left(\right.$ days $\left.^{-1}\right)$, respectively. Growth rate and biomass yield were 159 modulated with lactate as the limiting substrate. Any variability recorded in these experiments 160 should, thus, primarily reflect the isotopic response to changing sulfate concentrations. Our 161 approach allows us to measure the fractionation behavior of MSR at constant growth rates over a 162 range of sulfate concentrations (0.1 to $6.1 \mathrm{mM}$ ).

163 Sulfate and lactate were supplied to the bioreactors at rates necessary to achieve media 164 concentrations from 0.5 to $10 \mathrm{mM}$. As the limiting nutrient, standing lactate concentrations in 165 the chemostats were a function of dilution rate. The reactor vessel was continuously purged with 166 a pre-conditioned $\left(\mathrm{O}_{2}\right.$-free and hydrated) anaerobic gas mixture $\left(\mathrm{N}_{2}: \mathrm{CO}_{2}, 90: 10\right)$, which also 167 served to carry gas phase sulfide out of the reactor to a series of zinc acetate traps. Reactor $\mathrm{pH}$ 168 was maintained at $7.0 \pm 0.02$ via a $\mathrm{pH}$-probe activated titration pump, which dosed either $1 \mathrm{M} \mathrm{HCl}$ 169 or $1 \mathrm{M} \mathrm{NaOH}$ as appropriate $\left(\mathrm{N}_{2}\right.$-degassed and autoclave-sterilized). From the effluent, 170 concentrations of lactate/acetate and sulfate/sulfide were measured daily along with optical 171 density and all (gas and liquid) flow rates. Our reported concentrations are those measured from 172 the chemostat effluent, and represent the effective concentration of sulfate in the reactor. Steady173 state sulfate concentrations were measured directly from the bioreactor effluent, and represent 174 the concentration available to the population (lower than the concentration of the inlet media). 175 The fractionations of interest $\left({ }^{34} \varepsilon\right.$ and $\left.{ }^{33} \lambda\right)$ are thus between reactant sulfate and product sulfide, 176 both collected from the effluent. For isotopic analysis, all samples were measured for $\delta^{34} \mathrm{~S}$ via $177 \mathrm{SO}_{2}$ and select samples were fluorinated to $\mathrm{SF}_{6}$ and measured for high precision $\delta^{33} \mathrm{~S}$ analysis 178 (Johnston et al., 2005). Carbon and sulfur mass balances were always satisfied to within 2\%. 179 Growth rate was determined given growth data (cells $/ \mathrm{mL}$ or $\mathrm{A} 600 / \mathrm{mL}$ ) with respect to the 180 dilution rate $\left(\mathrm{D} \square\right.$ day $^{-1}$ ), and only samples satisfying a steady-state flow regime (see 
181 Supplemental Information) were included in the final analysis. All chemical, biological, and 182 isotopic methods are described in the supplemental materials.

\section{RESULTS AND DISCUSSION}

CHEMOSTAT EXPERIMENTS

The isotopic fractionation between sulfate and sulfide is plotted in Figure 1 as a function of the standing sulfate concentration in the chemostat for both $D$. vulgaris and $D$. alaskensis. Experiments with $D$. vulgaris yielded a range of ${ }^{34} \varepsilon_{\text {D.vulgaris }}$ from 18.0 to $32.7 \%$ over the targeted sulfate concentrations. Specifically, ${ }^{34} \varepsilon_{\text {D.vulgaris }}$ shows no significant covariance between sulfate concentration and fractionation $(p=0.19)$, meaning that there is no first-order dependence of

192 fractionation on sulfate concentration between 0.1 and $5 \mathrm{mM}$. Furthermore, D. vulgaris 193 demonstrates the capacity for significant isotope fractionation $\left({ }^{34} \varepsilon_{D . v u l g a r i s}\right.$ greater than $25 \%$, 194 although with significant scatter) at sulfate concentrations as low as $0.1 \mathrm{mM}$. These data are 195 consistent with a Michaelis-Menten type relationship between substrate concentration and 196 fractionation (Habicht et al., 2005), with a $K_{m-\text { frac }}=0.0027 \mathrm{mM}(95 \% \mathrm{CI}$ is 0 to $0.036 \mathrm{mM})$ 197 and ${ }^{34} \varepsilon_{\max }=25.8 \%$ (95\% CI is 23.4 to $28.3 \%$ ). $K_{m \text {-frac }}$ is defined as the sulfate concentration at 198 which expressed fractionation is one-half of the maximum fractionation under constant conditions excepting variable sulfate concentrations (Habicht et al., 2005).

In contrast, experiments with strain $D$. alaskensis produce a ${ }^{34} \varepsilon_{\text {D.alaskensis }}$ that varies 201 systematically from near 0 to $13 \%$ as steady-state sulfate concentrations are increased. These 202 data show strong co-variance, via the linear regression model: ${ }^{34} \varepsilon=(2.2 \pm 0.1) *\left[\mathrm{SO}_{4}{ }^{2-}\right]+(1.2 \pm$ 203 0.3), with a $p$-value less than 0.001 . This result is consistent with a first-order dependence 204 of ${ }^{34} \varepsilon_{\text {D.alaskensis }}$ on sulfate concentration over the range tested (0.1 to $6.1 \mathrm{mM}$ ). The data could also 205 be fit with a Michaelis-Menten type relationship, with a half-saturation constant of $K_{\mathrm{m} \text {-frac }}=8.9$ $206 \mathrm{mM}$ (95\% CI is 2.2 to $15.7 \mathrm{mM}$ ) and ${ }^{34} \varepsilon_{\max }$ of $34.5 \%$, $95 \%$ CI is 16.8 to $52.3 \%$ \%). Although 207 comparison of the two models using a corrected Akaike's ( $\mathrm{AIC}_{\mathrm{c}}$ ) information criterion favors the 208 linear model (62\% likelihood), mechanistic considerations (see 'Evaluation of cellular $K_{\mathrm{s}}$ ') 209 suggest that the Michaelis-Menten formulation is preferable. Taking the $D$. vulgaris and $D$. 210 alaskensis experiments together, the strains exhibits strikingly different patterns in both the 
211 magnitude of ${ }^{34} \varepsilon$ and its dependence on ambient sulfate concentration (i.e. the Michaelis-Menten 212 fitting parameters).

213 The relationship between sulfate concentration and isotopic fractionation $\left({ }^{34} \varepsilon\right)$ described 214 above and elsewhere (Habicht et al., 2002; Habicht et al., 2005) can be extended to include ${ }^{33}$ S. 215 These data are presented in Figure 2 using two complementary minor isotope notations ${ }^{\S}:{ }^{33} \lambda$ 216 and $\square \square \Delta^{33}$ S. The $\Delta^{33}$ S notation is common in geological applications and is the deviation (in \%o 217 units) from a theoretical reference frame defined using the calculated low temperature 218 thermodynamic equilibrium relationship between ${ }^{32} \mathrm{~S},{ }^{33} \mathrm{~S}$, and ${ }^{34} \mathrm{~S}$ where ${ }^{33} \lambda=0.515$. However, 219 since ${ }^{33} \lambda$ is not constant across various processes a calculation of its value provides another 220 measure of minor isotope variance - it can be envisioned as approximately the slope of the curve 221 on a plot of $\delta^{33} \mathrm{~S}$ vs. $\delta^{34} \mathrm{~S}$. Non-equilibrium processes can have slopes different than 0.515 , most 222 commonly less than 0.515 (Farquhar et al., 2003; Johnston et al., 2007). As both terms are 223 widely used, we plot both $\Delta^{33} S$ and ${ }^{33} \lambda$ versus ${ }^{34} \varepsilon$ (Fig. 2).

$224 \quad$ Previous studies targeting ${ }^{33} \lambda$ in open-system MSR experiments suggest that ${ }^{33} \lambda \square$ varies

225 linearly with $\delta^{34}$ S as a function of metabolic rate (Sim et al. 2011; Leavitt et al. 2013(Wu and 226 Farquhar, 2011)). As these slopes carry a metabolism-specific component (Johnston et al 2005), 227 the inclusion of ${ }^{33} \mathrm{~S}$ extends the biogeochemical utility of $\mathrm{S}$ isotopes. Including ${ }^{33} \mathrm{~S}$ allows the 228 effects of sulfate reduction to be discerned from those of sulfide oxidation or sulfur 229 disproportionation. For example, the ${ }^{34} \varepsilon_{\text {D.alaskensis }}$ values (0-13\%) expressed in our experiments by 230 strain D. alaskensis are not unique to MSR, as sulfide oxidation reactions often produce ${ }^{34} \varepsilon$ less 231 than $10 \%$. However, the inclusion of ${ }^{33} \mathrm{~S}$ provides an additional isotopic constraint that can be 232 used to trace the origin of sulfate and sulfide (Johnston et al., 2005). In our experiments, $\Delta^{33} \mathrm{~S}$ 233 and ${ }^{33} \lambda$ both show a strong relationship with ${ }^{34} \varepsilon$ (Fig. 2), and for $\Delta^{33} S: \Delta^{33} S=(0.0031 \pm$ $2340.0003) *\left({ }^{34} \varepsilon\right)+(0.20 \pm 0.01)$, $p$-value less than 0.0001. In this case $\mathrm{AIC}_{\mathrm{c}}$ favors a Michaelis235 Menten type fit (89\% likelihood) with a $K_{\mathrm{m}-\text { frac }}=20.1 \%$ [7.6 to $32.6 \%$ and $\Delta^{33} \mathrm{~S}_{\max }=0.169 \%$, 236 (95\% CI 0.110 to $0.228 \%$ ). The ${ }^{33} \lambda-{ }^{34} \varepsilon$ results for $D$. alaskensis and $D$. vulgaris fit within the 237 context of previous work in which ${ }^{33} \lambda_{\mathrm{MSR}}$ (dimensionless) spans a range from 0.508 to 0.514

\footnotetext{
${ }^{\S}$ We use standard isotope notation, where $\delta^{3 \mathrm{x}} \mathrm{S}$ is the ratio of ${ }^{3 \mathrm{x}} \mathrm{S}$ to ${ }^{32} \mathrm{~S}$ in a sample relative to a standard. We use ${ }^{34} \varepsilon$ to capture the isotopic difference between sulfate and sulfide $\left(=\left[{ }^{34} \alpha-1\right] 1000\right)$. Minor isotope notation includes $\Delta^{33} \mathrm{~S}\left(=\delta^{33} \mathrm{~S}+1000\left[\delta^{34} \mathrm{~S} / 1000+1\right]^{0.515}-1\right)$, which relates a composition to a theoretical reference line, and ${ }^{33} \lambda\left(=\ln \left[{ }^{33} \alpha\right] / \ln \left[{ }^{34} \alpha\right]\right)$, which is approximately the slope of the tangent to the curve of $\delta^{33} \mathrm{~S}$ vs. $\delta^{34} \mathrm{~S}$.
} 
238 (Farquhar et al. 2003; Johnston et al. 2005; 2007; Sim et al. 2011; Leavitt et al. 2013). In 239 contrast, sulfide oxidation and sulfur disproportionation reactions result in ${ }^{33} \lambda$ greater than

2400.5145 (Johnston et al., 2005; Zerkle et al., 2009). Therefore, these data support minor sulfur 241 isotopes as a quantitative indicator of specific metabolism, despite control on fractionation of 242 other experimental parameters like sulfate (e.g., temperature, MSR strain, etc.).

\section{EVALUATION OF CELLULAR $\boldsymbol{K}_{\mathrm{S}}$ AS A PREDICTOR OF FRACTIONATION}

245 These experiments demonstrate that different strains of sulfate reducing bacteria can 246 show distinct relationships between sulfate concentration and isotope fractionation. The observed 247 differences prompt a reexamination of previous data and reinvigorate the search for similar 248 patterns. Harrison and Thode (1958) demonstrated a correlation between sulfate concentration 249 and sulfur isotope fractionation with $D$. desulfuricans. More recent work using modified flow250 through reactors (Habicht et al., 2002) and a recirculating chemostat (Habicht et al., 2005) shows 251 a relationship in which ${ }^{34} \varepsilon$ increases with sulfate concentration, and can be interpreted as 252 asymptotically approaching a maximum value. This later work targeted the MSR Archaeoglobus 253 fulgidus, a hyperthermophilic Archaea. In those studies, growth and cell specific sulfate 254 reduction rate (csSRR) were controlled through organic carbon limitation, and the threshold 255 effect of sulfate concentrations (i.e., a step function) was observed. The authors modeled this 256 asymptotic behavior with an equation identical in form to a Michaelis-Menten equation although 257 a linear fit to these data cannot be excluded without a theoretical justification (see below). The 258 half-saturation constant in this fractionation equation $\left(K_{\mathrm{m}-\text { frac }}\right)$ is then defined as the 259 concentration of sulfate at which the modeled fractionation was one-half the maximum

260 fractionation. The value of $K_{\mathrm{m} \text {-frac }}$ for sulfate was similar in magnitude to the Michaelis-Menten 261 half-saturation constant $\left(K_{s}\right)$ for sulfate-limited growth. The similarity in these constants inspired 262 the proposition that $K_{\mathrm{m} \text {-frac }}$ and $K_{\mathrm{s}}$ are directly (linearly) related, implying that the half saturation 263 constant carries an isotopic - and perhaps geologic - fingerprint (Habicht et al., 2002).

264 A Michaelis-Menten -like mathematical relationship correctly predicts the fractionation 265 pattern displayed by $D$. vulgaris. Previous work indicates a $K_{\mathrm{s}}$ for sulfate in $D$. vulgaris near $2660.03 \mathrm{mM}$ (Ingvorsen and Jørgensen, 1984), well below the sulfate concentrations in our 267 experiments. If $K_{\mathrm{m} \text {-frac }}$ is of a similar magnitude, as predicted by our measurements at millimolar 268 sulfate, then at our minimum sulfate concentration of $0.1 \mathrm{mM}$, we expect to observe more than 
$90 \%$ of the maximum fractionation under the specific experimental conditions (i.e. csSRR and chemostat dilution rate) employed (Fig. 1; see Materials and Methods). Only a modest increase

271 in fractionation would accompany further increases in sulfate concentrations, consistent with our

272 observations for $D$. vulgaris. Changes in csSRR would have more dramatic consequences.

273 In contrast, a Michaelis-Menten-like equation can only explain the experimental results

274 for strain $D$. alaskensis if the $K_{\mathrm{m} \text {-frac }}$ is quite large - greater than the experimental window 275 investigated here $\left(K_{\mathrm{m}-\text { frac }}=8.9 \mathrm{mM}, 95 \% \mathrm{CI}\right.$ is 2.2 to $\left.15.7 \mathrm{mM}\right)$. We are unaware of any 276 published sulfate $K_{\mathrm{s}}$ values from strain $D$. alaskensis specifically, although $K_{\mathrm{s}}$ values from 277 related strains (D. desulfuricans) are consistently less than $0.5 \mathrm{mM}$ (Tarpgaard et al., 2011) 278 eighteen-fold lower than would be required if $K_{\mathrm{m} \text {-frac }}$ and $K_{\mathrm{s}}$ are to be similar. Given that the $D$. 279 alaskensis genome contains at least 10 putative sulfate transporters, the cellular $K_{\mathrm{s}}$ for sulfate is 280 likely highly dependent on growth conditions. One plausible explanation for the observed result 281 is that under these conditions $D$. alaskensis expresses only low affinity sulfate transporters, and 282 that a functional relationship between $K_{\mathrm{s}}$ and $K_{\mathrm{m} \text {-frac }}$ holds. Indeed, a sulfate $K_{\mathrm{s}}$ of this 283 magnitude is within the upper limits of published $K_{\mathrm{s}}$ values for sulfate (Fukui and Takii, 1994; 284 Ingvorsen et al., 1984; Pallud and Van Cappellen, 2006; Roychoudhury, 2004; Tarpgaard et al., 285 2011).

286 These new data highlight the fact that the relationship between cellular $K_{\mathrm{s}}$ for sulfate and 287 isotope fractionation remains unclear, and affinity $\left(A_{\mathrm{s}}\right)$ may be a more appropriate term to use 288 when examining MSR in the context of environmental conditions. While $K_{\mathrm{s}}$ values for sulfate 289 are directly related to the kinetics of growth under sulfate-limited conditions, experiments on the 290 fractionation of sulfur isotopes are generally executed under electron donor limitation or co291 limitation of sulfate and electron donor (e.g., this study, Habicht et al. 2002, 2005). Growth and 292 sulfate reduction rates are therefore directly related to the affinity $\left(A_{s}\right)$ for the electron donor 293 relative to that of sulfate, rather than simply sulfate concentrations. Sulfate $K_{\mathrm{s}}$ pertains only to 294 the cellular half-saturation constant for sulfate and may affect fractionation, particularly when 295 sulfate is not growth-limiting. In more detail, sulfate transport in sulfate-reducing 296 microorganisms is strictly regulated, and is accomplished via numerous possible mechanisms. 297 These include $\mathrm{H}^{+}$and $\mathrm{Na}^{+}$symporters, which rely on concentration gradients and do not require 298 ATP (Cypionka, 1995), whereas there also exist ATP-dependent ABC-type active transporters 299 that pump sulfate into the cell against a concentration gradient (Piłsyk and Paszewski, 2009) and 
300 are homologous to enzymes for assimilatory sulfate transport in other (non-sulfate-reducing) 301 microorganisms. Energetic considerations favor the symporters as the primary transport 302 mechanism for dissimilatory metabolism (Cypionka, 1995). Regulation of various transporters 303 with different affinities (Cypionka, 1995; Tarpgaard et al., 2011) probably allows the cells to 304 adapt to various sulfate concentrations; with high-affinity transporters up-regulated at low sulfate 305 concentrations and vice versa. Therefore, one plausible explanation for the apparently divergent 306 patterns in Fig. 1 is that transport mechanisms differ between $D$. vulgaris and D. alaskensis. For 307 example, if under similar conditions $D$. vulgaris expressed high affinity sulfate transporters, its 308 concentration (Habicht et al., 2002) and specific sulfate reduction rate (Chambers and Trudinger, 1975; Harrison and Thode, 1958; Leavitt et al., 2013; Sim et al., 2011c), it would be useful to understand the interaction of these two variables. Both can be related to the cellular machinery 318 for sulfate reduction by comparing the independent rates of sulfate and electron supply to the cell 319 (Bradley et al., 2011). Sulfur isotope fractionation will be maximized when intracellular sulfate 320 concentrations are unlimited and electron supplies are limited. This is the situation that occurs at 321 very low growth rates: electron donor limits the growth rate, but if sulfate is not limiting then 322 cellular transport of sulfate should not be limiting either. We can conceptualize this growth state 323 as a high supply of sulfate relative to electrons.

325 cells are able to obtain sufficient electrons to quantitatively reduce sulfate to sulfide, then 326 expressed fractionation will be zero. This situation occurs when cells import electrons (via 327 electron donors) sufficiently quickly that all imported sulfate is reduced to sulfide. The 328 relationship between sulfur delivery and electron delivery is mechistically expressed at key 329 enzymes in the sulfate reduction pathway. For example, the enzyme dissimilatory sulfite 
330 reductase requires three components to function (Figure 4): i) electrons, delivered via an

331 intracellular electron carrier, ii) sulfite

332 Therefore, to a first order fractionation is proportional to the rate at which sulfate can be

333 imported into the cell, and inversely proportional to the rate at which electrons are imported into

334 the cell.

$335[1]$

$$
{ }^{34} \mathcal{E} \sim \frac{v_{\text {sulfate }}}{v_{\text {electrons }}}
$$

336 where ${ }^{34} \varepsilon$ is the expressed fractionation, $v_{\text {sulfate }}$ is the rate at which sulfate is supplied to 337 the cell. This rate is dependent on the kinetics of sulfate transporters, and is classically 338 approximated as an Michaelis-Menten relationship:

$$
\boldsymbol{v}_{\text {sulfate }}=\frac{\boldsymbol{v}_{\text {max }}^{\text {sulfate }}\left[\mathrm{SO}_{4}^{2-}\right]}{\boldsymbol{K}_{s}^{\text {sulfate }}+\left[\mathrm{SO}_{4}^{2-}\right]} .
$$

The rate of sulfate reduction is similarly controlled, in a cell with excess sulfate, by the

341 rate of electron supply to the reduction machinery. The rate that electron donors are imported can

342 similarly be modeled as a Michaelis-Menten relationship, with different kinetic parameters for 343 different electron donors. However, for the purposes of understanding fractionation the important 344 parameter is the rate that electrons are supplied for the reduction of sulfate. This rate is 345 proportional to the cell-specific sulfate reduction rate:

$$
\boldsymbol{v}_{\text {electrons }} \sim \operatorname{csSRR}
$$

Combining these two relationships, the observed fractionation is proportional to the MM relationship for sulfate import, times the inverse of the cell-specific sulfate reduction rate.

This relationship has two consequences, both of which have been demonstrated 352 empirically: first, at a given csSRR the relationship between sulfate concentration and sulfur 353 isotope fractionation follows a curve that can be represented as a Michaelis-Menten curve 354 (Habicht et al., 2005); second, at a given sulfate concentration the relationship between csSRR 355 and fractionation is a nonlinear (hyperbolic) function of csSRR (Desmond-Le Quéméner and 356 Bouchez, 2014; Leavitt et al., 2013; Sim et al., 2011c; Wing and Halevy, 2014). This equation 357 can be related to that given by Habicht et al. (2005), where 


$$
{ }^{34} \varepsilon=\frac{\varepsilon_{\max }\left[\mathrm{SO}_{4}^{2-}\right]}{K_{m-\text { frac }}+\left[\mathrm{SO}_{4}^{2-}\right]}=\frac{V_{\max }^{\text {sulfate }}\left[\mathrm{SO}_{4}^{2-}\right]}{K_{s}^{\text {sulfate }}+\left[\mathrm{SO}_{4}^{2-}\right]} \frac{\gamma}{v_{\mathrm{sT}}}
$$

359 and where $\gamma$ represents a factor for the conversion from rate to fractionation; this may differ 360 from one strain to another. In this formulation $K_{\mathrm{s}}$ and $K_{\mathrm{m} \text {-frac }}$ are related, but distinct, values and 361 the relationship between them depends on both the strains involved and the csSRR. In this 362 formulation, $\varepsilon_{\max }$ (and therefore $\gamma$ ) is a function of csSRR, with a maximum value at low rates 363 resulting in a fractionation equivalent to the thermodynamic equilibrium fractionation factor 364 between sulfate and sulfide.

365 Given a single strain and concentration of electron donor, as is the case with our 366 chemostat experiments, sulfate reduction rate is invariant, and the variation in fractionation 367 would approximate a Michaelis-Menten curve on sulfate concentration, as shown by Habicht et 368 al. (2005) (Figure 5A). Moreover, the apparent $K_{\mathrm{m} \text {-frac }}$ need not be the same from strain to strain, 369 and this is reflected in the data herein on D. vulgaris and D. alaskensis at the same SRR. The 370 value primarily depends on both the strain-specific half-saturation constant for sulfate and the 371 kinetic parameters related to transport of the electron donor. High sulfate concentrations and low 372 growth rates (as limited by electron donor) both drive fractionations towards maximum 373 (equilibrium-like) values. At constant sulfate concentrations, the relationship between 374 fractionation and csSRR would have the hyperbolic relationship shown in Figure 5B and 375 demonstrated in previous studies (Leavitt et al., 2013; Sim et al., 2011c). This hyperbolic 376 relationship is conceptually similar to the relationship between carbon dioxide concentrations

377 and ${ }^{13} \varepsilon$ discrimination against carbon isotopes demonstrated during carbon assimilation (Laws et 378 al., 1995; Popp et al., 1998). However, that is a linear relationship since $\mathrm{CO}_{2}$ assimilation and 379 growth rate are directly related.

\section{FACTORS GOVERNING S ISOTOPE FRACTIONATION BY SRB}

We propose that controls on $\mathrm{S}$ isotopic fractionation can generally be divided into four 383 regimes, only a subset of which have been the foci of experimental research to date (Figure 6). 384 Within each regime, transport and physiological factors will affect observed fractionation.

385 Sulfate limitation: in this regime, sulfate (terminal electron acceptor) availability limits 386 the rate of sulfate reduction. Due to quantitative, or near-quantitative reduction of sulfate, 
387 expressed fractionation is small or may even carry a small inverse isotope effect (Harrison and 388 Thode, 1958).

Electron donor limitation: In this case, both sulfate concentration and csSRR are relevant to determining fractionation factors. At lower sulfate concentrations this parameter is still 391 influential on fractionation so long as sulfate is not being quantitatively reduced (Regime I), 392 while at higher sulfate concentrations ( $28 \mathrm{mM}$, i.e. higher than two times the $K_{\mathrm{m}-\mathrm{frac}}$ ), rate is 393 primarily determined by electron donor availability. This is the regime that is the focus of most 394 studies on the magnitude of sulfur isotope fractionation (Chambers and Trudinger, 1975; Kaplan 395 and Rittenberg, 1964; Leavitt et al., 2013; Sim et al., 2011a; Sim et al., 2011c).

Substrate co-limitation: Concentrations of both sulfate and electron donor are low relative to the cellular affinities. Growth rate in this case may be a second-order function that relates to the concentration and affinity of both substrates, or it may be the minimum growth rate predicted by either parameter (Liebig's law: (Saito et al., 2008)). Under these conditions, the expressed fractionation is likely to be a compound function of physiology and environment making fractionation difficult to uniquely predict. Moreover, large fractionations are not excluded from this regime (Wing and Halevy, 2014), and significant fractionations have been 403 observed at low sulfate concentrations (Canfield et al., 2010; Crowe et al., 2014; Gomes and 404 Hurtgen, 2013; Nakagawa et al., 2012). If limitation of one constituent exerts ultimate control, 405 then the system reverts to regime 1 or 2.

$406 \quad$ Nutrient or physical limitation(s): There can be other nutrients or factors - such as 407 nitrogen, iron, or phosphorous limitation (Sim et al., 2012), a physical factor (e.g. 408 temperature,(Canfield et al., 2006; Johnston et al., 2007)) or an intrinsic organismal factor that 409 limits growth rate and fractionation. The rate-fractionation relationship has been demonstrated 410 for electron donor/acceptor (Canfield, 2001; Chambers et al., 1975; Kaplan and Rittenberg, 411 1964; Leavitt et al., 2013; Sim et al., 2011a; Sim et al., 2011c) and for nutrients (Sim et al., 412 2012), and can plausibly extend to other parameters. Where growth rates are controlled by 413 factors intrinsic to the cell (e.g. in most batch culture experiments, during early log-phase 414 growth), expressed fractionations are likely to reflect rates of intracellular electron transport to 415 electron-accepting sulfur intermediates, described above (Bradley et al., 2011). Under severely 416 limited conditions it may be possible to approach equilibrium isotope fractionations (Wing and 417 Halevy, 2014). 
These regimes indicate that multiple interactions ultimately control the sulfur isotope

419 fractionation expressed by any given organism in any particular environment. As mentioned

420 above, one physiological component not yet explored is the potential for organisms to carry

421 multiple sulfate uptake machineries of varying affinities. For example, as sulfate is consumed

422 through a typical marine sedimentary early diagenetic profile (Jorgensen, 1979), the sulfate

423 concentrations available for MSR vary from 28 to less than $1 \quad$ Pd\$sessing high affinity

424 sulfate transporters may confer a selective advantage at low concentrations, whereas low affinity

425 transporters may confer an advantage at high ambient sulfate. A recent study identified both high

426 and low affinity uptake mechanisms through a sulfate-methane transition zone profile in marine

427 sediments (Tarpgaard et al., 2011), showing that large differences in affinity are possible even

428 within the microbial community from a specific environment. Optimization of cellular

429 machinery for the acquisition of metabolites is observed in other metabolic processes. For

430 example, carbon fixation by RuBisCO is optimized to intracellular $\mathrm{CO}_{2} / \mathrm{O}_{2}$ ratios (Tcherkez et

431 al., 2006). The genome of D. vulgaris (Heidelberg et al., 2004) contains three annotated sulfate

432 transport proteins, while the genome of D. alaskensis contains at least ten (Hauser et al., 2011).

433 This redundancy is consistent with a potential range of affinities and could be further extended if

434 unknown transport proteins are also present. In a microbial community with a mixture of

435 organisms, each with a potential range of transporters, the overall observed fractionation will

436 depend on how each member of the community processes sulfate and discriminate against its

437 heavier isotopes.

438 An apparent range in affinities of enzymatic machinery for sulfate sets in place a 439 prediction for an affinity continuum at the organismic level. The $V_{\max } / K_{\mathrm{s}}$ expressed under any set

440 of conditions is physiologically dependent and may incorporate feedbacks sensitive to sulfate 441 concentration. The presence of both high and low affinity uptake mechanisms, at the cellular and 442 community scales, is relevant to interpretation of the geochemical record. Continuing research 443 will need to identify the full genetic and enzymatic controls on sulfate affinity in a variety of 444 organisms, as well as the selective pressures to which these controls respond. In the future, more 445 robust geochemical interpretations of sulfur isotopes may be achieved by furthering our 446 understanding of how sulfate affinity has evolved in response to changing marine redox 447 conditions and oxidant budgets (i.e. sulfate availability due to oxidative weathering), and how 448 this evolution has influenced the sulfur isotope record. A high affinity for sulfate would have 
449 been particularly advantageous early in Earth history, with the requirement becoming more 450 relaxed as the Earth's surface became more oxidizing and sulfate more plentiful. That is, natural 451 selection has likely altered dominant patterns of sulfur isotope fractionation over the course of

452 Earth history. A genomic memory of ancient high affinity machinery may still be present in 453 modern lacustrine environments, or other factors such as ecological competition may continue to 454 select for those capacities. As new genomes and tools for analyzing molecular evolution become 455 available, these questions become more tractable.

\section{CONCLUSIONS}

Understanding the paleoenvironmental information encoded in sulfur isotopes during sulfate reduction requires an understanding of how growth and physiology affect stable isotope 460 fractionation (Bradley et al., 2011; Rees, 1973). De-convolving these effects becomes tractable 461 through experimental and theoretical exploration, such as further elucidating the $V_{\max } / K_{\mathrm{s}}$ 462 relationship $\left(A_{s}\right)$ with $K_{\mathrm{m}-\text { frac }}$, which serves as a practical means of comparing fractionation data 463 from different strains. It is clear that there is no unequivocal sulfate threshold concentration 464 related to a step function in sulfur isotope fractionation across all strains, and it is unclear which 465 strains, adapted to the modern environment, are the best proxies for Archaean microbial 466 processes. Described here as a physiological and kinetic phenomenon, our framework for 467 understanding fractionation helps explain recent observations of large ${ }^{34} \varepsilon$ in low sulfate lake 468 systems (Gomes and Hurtgen, 2013; Nakagawa et al., 2012). If the fractionation by MSR is in 469 fact linked to multiple environmental and physiological variables, where each exhibit complex 470 and non-linear (MM-like) responses, then articulating a clear heuristic for interpreting geological 471 records is more challenging. Using sulfur isotopes to constrain sulfate concentrations in the 472 Archean ocean is challenging, since the physiological parameters (affinity towards sulfate and 473 electron donor) of Archaean microbes is unknown. Sulfate concentrations less than $200 \mu \mathrm{M}$ are 474 one explanation for small fractionations. It is also possible that small fractionations resulted from 475 microbes with physiologies more like D. alaskensis than like D. vulgaris. Another alternative for 476 small fractionations in Achaean seawater is that biological fractionations may have been large, 477 but reservoir effects suppressed fractionation through reservoir effects \{Crowe, 2014 \#4561\}. 478 Independent approaches for understanding the chemistry of Archean seawater (Jamieson et al., 479 2012) (Halevy et al., 2010; Halevy et al., 2012) can help constrain sulfate concentrations and 
480 shed light on the interpretation of sulfur isotopes in light of both seawater chemistry and 481 evolution. A more complete understanding of the sulfur isotope record will rely on building a 482 better understanding of the relevant enzymes, their expression and isotope fractionation in 483 response to environmental variables, and their evolution over the course of Earth history.

484

485 


\section{ACKNOWLEDGMENTS}

488 Many thanks to Gill Geesey and Inês Cardoso-Pereira for providing cultures of D. alaskensis 489 G20 and D. vulgaris Hildenborough, respectively. Andy Masterson, Erin Beirne, and Madeline 490 Higgins provided expert analytical assistance. The authors acknowledge funding from NASA 491 Exobiology Grant NNX07AV51G (to AHK, PRG and DTJ), NASA Astrobiology Institute (DTJ, 492 AHK), the Microbial Sciences Initiative at Harvard (DTJ), NSF EAR Instrument and Facilities 493 as well as Low Temperature Geochemistry and Geobiology (to DTJ), NSF Graduate Research 494 Fellowship (WDL) and the Agouron Institute (ASB).

496 SUPPLEMENTAL INFORMATION:

497 Materials \& Methods

498 Supplemental File $1-D$. vulgaris growth data

499 Supplemental File 2 - D. alaskensis growth data

500

501 
Aksnes, D.L., Egge, J.K., 1991. A theoretical model for nutrient uptake in phytoplankton. Marine Ecology Progress Series 70, 65-72.

Bak, F., Pfennig, N., 1991. MICROBIAL SULFATE REDUCTION IN LITTORAL SEDIMENT OF LAKE CONSTANCE. Fems Microbiology Ecology 85, 31-42.

Berner, R.A., Canfield, D.E., 1989. A new model for atmospheric oxygen over Phanerozoic time. American Journal of Science 289, 333-361.

Bradley, A.S., Leavitt, W.D., Johnston, D.T., 2011. Revisiting the dissimilatory sulfate reduction network. Geobiology 9, 446-457.

Button, D.K., 1985. Kinetics of nutrient-limited transport and microbial growth. Microbiological reviews 49, 270-297.

Canfield, D., E., 2001. Isotope fractionation by natural populations of sulfate-reducing bacteria. 65, 1117-1124.

Canfield, D.E., 2004. The evolution of the Earth surface sulfur reservoir. American Journal of Science 304, 839-861.

Canfield, D.E., Farquhar, J., Zerkle, A.L., 2010. High isotope fractionations during sulfate reduction in a low-sulfate euxinic ocean analog. Geology 38, 415-418.

Canfield, D.E., Olesen, C.A., Cox, R.P., 2006. Temperature and its control of isotope fractionation by a sulfate-reducing bacterium. Geochimica et Cosmochimica Acta 70, 548-561.

Chambers, L.A., Trudinger, P.A., 1975. Are thiosulfate and trithionate intermediates in dissimilatory sulfate reduction? Journal of Bacteriology 123, 36-40.

Chambers, L.A., Trudinger, P.A., Smith, J.W., Burns, M.S., 1975. Fractionation of sulfur isotopes by continuous cultures of Desulfovibrio desulfuricans. Canadian Journal of Microbiology 21, 1602-1607.

Crowe, S.A., Paris, G., Katsev, S., Jones, C., Kim, S.-T., Zerkle, a.L., Nomosatryo, S., Fowle, D.A., Adkins, J.F., Sessions, A.L., Farquhar, J., Canfield, D.E., 2014. Sulfate was a trace constituent of Archean seawater. Science 346, 735-739.

Cypionka, H., 1995. Solute transport and cell energetics. In: L. Barton (Ed.), Sulfate-Reducing Bacteria, pp. 151-184. Plenum Press, New York.

Dalsgaard, T., Bak, F., 1994. NITRATE REDUCTION IN A SULFATE-REDUCING BACTERIUM, DESULFOVIBRIO-DESULFURICANS, ISOLATED FROM RICE PADDY SOIL - SULFIDE INHIBITION, KINETICS, AND REGULATION. Applied and environmental microbiology 60, 291-297.

Desmond-Le Quéméner, E., Bouchez, T., 2014. A thermodynamic theory of microbial growth. The ISME Journal 8, 1747-1751.

Farquhar, J., Johnston, D.T., Wing, B.A., Habicht, K.S., Canfield, D.E., Airieau, S., Thiemens, M.H., 2003. Multiple sulphur isotopic interpretations of biosynthetic pathways: implications for biological signatures in the sulphur isotope record. Geobiology 1, 27-36.

Fukui, M., Takii, S., 1994. Kinetics of sulfate respiration by free-living and particle-associated sulfate-reducing bacteria. Fems Microbiology Ecology 13, 241-247.

Gomes, M.L., Hurtgen, M.T., 2013. Sulfur isotope systematics of a euxinic, low-sulfate lake: evaluating the importance of the reservoir effect in modern and ancient oceans. Geology $41,663-666$. 
Grein, F., Ramos, A.R., Venceslau, S.S., Pereira, I.A.C., 2013. Unifying concepts in anaerobic respiration: insights from dissimilatory sulfur metabolism. Biochimica et Biophysica Acta 1827, 145-160.

Habicht, K.S., Gade, M., Thamdrup, B., Berg, P., Canfield, D.E., 2002. Calibration of sulfate levels in the Archean Ocean. Science 298, 2372-2374.

Habicht, K.S., Salling, L., Thamdrup, B., Canfield, D.E., 2005. Effect of Low Sulfate Concentrations on Lactate Oxidation and Isotope Fractionation during Sulfate Reduction by Archaeoglobus fulgidus Strain Z. Applied and environmental microbiology 71, 37703777.

Halevy, I., Johnston, D.T., Schrag, D.P., 2010. Explaining the structure of the Archean massindependent sulfur isotope record. Science 329, 204-207.

Halevy, I., Peters, S.E., Fischer, W.W., 2012. Sulfate Burial Constraints on the Phanerozoic Sulfur Cycle. Science (New York, NY) 337, 331-334.

Hansen, T., 1994. Metabolism of sulfate-reducing prokaryotes. Antonie van Leeuwenhoek 66, 165-185.

Harrison, A., Thode, H., 1958. Mechanism of the bacterial reduction of sulphate from isotope fractionation studies. Transactions of the Faraday Society 54, 84-92.

Hauser, L.J., Land, M.L., Brown, S.D., Larimer, F., Keller, K.L., Rapp-Giles, B.J., Price, M.N., Lin, M., Bruce, D.C., Detter, J.C., Tapia, R., Han, C.S., Goodwin, L.A., Cheng, J.F., Pitluck, S., Copeland, A., Lucas, S., Nolan, M., Lapidus, A.L., Palumbo, A.V., Wall, J.D., 2011. Complete Genome Sequence and Updated Annotation of Desulfovibrio alaskensis G20. Journal of Bacteriology 193, 4268-4269.

Hayes, J.M., Waldbauer, J.R., 2006. The carbon cycle and associated redox processes through time. Philosophical Transactions of the Royal Society B-Biological Sciences 361, 931950.

Healey, F.P., 1980. Slope of the Monod equation as an indicator of advantage in nutrient competition. Microbial Ecology 5, 281-286.

Heidelberg, J.F., Seshadri, R., Haveman, S.A., Hemme, C.L., Paulsen, I.T., Kolonay, J.F., Eisen, J.A., Ward, N., Methé, B., Brinkac, L.M., Daugherty, S.C., Deboy, R.T., Dodson, R.J., Durkin, A.S., Madupu, R., Nelson, W.C., Sullivan, S.A., Fouts, D., Haft, D.H., Selengut, J., Peterson, J.D., Davidsen, T.M., Zafar, N., Zhou, L., Radune, D., Dimitrov, G., Hance, M., Tran, K., Khouri, H., Gill, J., Utterback, T.R., Feldblyum, T.V., Wall, J.D., Voordouw, G., Fraser, C.M., 2004. The genome sequence of the anaerobic, sulfatereducing bacterium Desulfovibrio vulgaris Hildenborough. Nature Biotechnology 22, 554-559.

Holmer, M., Storkholm, P., 2001. Sulphate reduction and sulphur cycling in lake sediments: a review. Freshwater Biology 46, 431-451.

Ingvorsen, K., Jørgensen, B.B., 1984. Kinetics of sulfate uptake by freshwater and marine species of Desulfovibrio. Archives of Microbiology 139, 61-66.

Ingvorsen, K., Zehnder, A.J.B., Jorgensen, B.B., 1984. KINETICS OF SULFATE AND ACETATE UPTAKE BY DESULFOBACTER-POSTGATEI. Applied and environmental microbiology 47, 403-408.

Jamieson, J.W., Wing, B.A., Farquhar, J., Hannington, M.D., 2012. Neoarchaean seawater sulphate concentrations from sulphur isotopes in massive sulphide ore. Nature Geoscience 6, 61-64. 
591

592

593

594

595

596

597

598

599

600

601

602

603

604

605

606

607

608

609

610

611

612

613

614

615

616

617

618

619

620

621

622

623

624

625

626

627

628

629

630

631

632

633

634

635

Johnston, D., Farquhar, J., Canfield, D., 2007. Sulfur isotope insights into microbial sulfate reduction: When microbes meet models. Geochimica et Cosmochimica Acta 71, 39293947.

Johnston, D.T., Farquhar, J., Wing, B.A., Kaufman, A.J., Canfield, D.E., Habicht, K.S., 2005. Multiple sulfur isotope fractionations in biological systems: A case study with sulfate reducers and sulfur disproportionators. American Journal of Science 305, 645-660.

Jorgensen, B.B., 1979. Theoretical model of the stable isotope distribution in marine sediments. Geochimica et Cosmochimica Acta 43, 363-374.

Kaplan, I., Rittenberg, S., 1964. Microbiological fractionation of sulfur isotopes. Journal of General Microbiology 34, 195-\&.

Laws, E.A., Popp, B.N., Bidigare, R.R., Kennicutt, M.C., Macko, S.A., 1995. Dependence of phytoplankton carbon isotopic composition on growth rate and [CO2]aq: theoretical considerations and experimental results. Geochimica et Cosmochimica Acta 59, 1131-8.

Leavitt, W.D., Halevy, I., Bradley, A.S., Johnston, D.T., 2013. Influence of sulfate reduction rates on the Phanerozoic sulfur isotope record. Proceedings of the National Academy of Sciences, in press.

Nakagawa, M., Ueno, Y., Hattori, S., Umemura, M., Yagi, A., Takai, K., Koba, K., Sasaki, Y., Makabe, A., Yoshida, N., 2012. Seasonal change in microbial sulfur cycling in monomictic Lake Fukami-ike, Japan. Limnology and Oceanography 57, 974-988.

Okabe, S., Nielsen, P.H., Characklis, W.G., 1992. FACTORS AFFECTING MICROBIAL SULFATE REDUCTION BY DESULFOVIBRIO-DESULFURICANS IN CONTINUOUS CULTURE - LIMITING NUTRIENTS AND SULFIDE CONCENTRATION. Biotechnology and Bioengineering 40, 725-734.

Pallud, C., Van Cappellen, P., 2006. Kinetics of microbial sulfate reduction in estuarine sediments. Geochimica Et Cosmochimica Acta 70, 1148-1162.

Pereira, I.A.C., Ramos, A.R., Grein, F., Marques, M.C., da Silva, S.M., Venceslau, S.S., 2011. A comparative genomic analysis of energy metabolism in sulfate reducing bacteria and archaea. Frontiers in Microbiology 2, Article 69.

Piłsyk, S., Paszewski, A., 2009. Sulfate permeases-phylogenetic diversity of sulfate transport. Acta Biocimica Polonica 56, 375-384.

Popp, B.N., Laws, E.A., Bridigare, R.R., Dore, J.E., Hanson, K.L., Wakeham, S.G., 1998. Effect of phytoplankton cell geometry on carbon isotopic fractionation. Geochimica et Cosmochimica Acta 62, 69-77.

Rees, C.E., 1973. Steady-state model for sulfur isotope fractionationin bacterial reduction processes. Geochimica et Cosmochimica Acta 37, 1141-1162.

Roychoudhury, A.N., 2004. Sulfate respiration in extreme environments: A kinetic study. Geomicrobiology Journal 21, 33-43.

Saito, M.A., Goepfert, T.J., Ritt, J.T., 2008. Some thoughts on the concept of colimitation: Three definitions and the importance of bioavailability. Limnology and Oceanography 53, 276290.

Sim, M.S., Bosak, T., Ono, S., 2011a. Large Sulfur Isotope Fractionation Does Not Require Disproportionation. Science (New York, NY) 333, 74-77.

Sim, M.S., Ono, S., Bosak, T., 2012. Effects of Iron and Nitrogen Limitation on Sulfur Isotope Fractionation during Microbial Sulfate Reduction. Applied and environmental microbiology 78, 8368-8376 \%R 10.1128/AEM.01842-12. 
Sim, M.S., Ono, S., Donovan, K., Templer, S.P., Bosak, T., 2011c. Effect of electron donors on the fractionation of sulfur isotopes by a marine Desulfovibrio sp. Geochimica et Cosmochimica Acta 75, 4244-4259.

Smith, S.L., Yamanaka, Y., Pahlow, M., Oschlies, A., 2009. Optimal uptake kinetics: physiological acclimation explains the pattern of nitrate uptake by phytoplankton in the ocean. Marine Ecology Progress Series 384, 1-12.

Szabo, A., Tudge, A., Macnamara, J., Thode, H.G., 1950. The distribution of S-34 in nature and the sulfur cycle. Science 111, 464-465.

Tarpgaard, I.H., Røy, H., Jørgensen, B.B., 2011. Concurrent low- and high-affinity sulfate reduction kinetics in marine sediment. Geochimica et Cosmochimica Acta 75, 2997-3010.

Tcherkez, G.G.B., Farquhar, G.D., Andrews, T.J., 2006. Despite slow catalysis and confused substrate specificity, all ribulose bisphosphate carboxylases may be perfectly optimized. Proceedings of the National Academy of Sciences 103, 7246-7251.

Venceslau, S.S., Stockdreher, Y., Dahl, C., Pereira, I.A.C., 2014. The "bacterial heterodisulfide" DsrC is a key protein in dissimilatory sulfur metabolism. Biochimica et Biophysica Acta 1837, 1148-1164.

Wall, J.D., Rapp-Giles, B.J., Rousset, M., 1993. Characterization of a small plasmid from Desulfovibrio desulfuricans and its use for shuttle vector construction. Journal of Bacteriology 1775, 4121-4128.

Wing, B.A., Halevy, I., 2014. The sulfur isotope phenotypes of sulfate-respiring bacteria and archaea. Proceedings of the National Academy of Sciences, in press.

Wu, N., Farquhar, J., 2011. Metabolic rates and sulfur cycling in teh geologic record. Proceedings of the National Academy of Sciences 110, 11217-11218.

Zerkle, A.L., Farquhar, J., Johnston, D.T., Cox, R.P., Canfield, D.E., 2009. Fractionation of multiple sulfur isotopes during phototrophic oxidation of sulfide and elemental sulfur by a green sulfur bacterium. Geochimica et Cosmochimica Acta 73, 291-306. 
Figure 1. Sulfate concentrations in each chemostat experiment at steady-state and the resulting strain-specific major isotope fractionation between sulfate and sulfide $\left({ }^{34} \varepsilon_{\mathrm{SO} / \mathrm{H} 2 \mathrm{~S}}\right)$. Samples for isotope measurements are taken at steady-state sulfate concentrations. Strain Desulfovibrio vulgaris Hildenborough (red) exhibits larger isotope effects across the full range of sulfate concentrations, whereas strain Desulfovibrio alaskensis strain G20 (blue) shows strong 670 concentration dependence.

672 Figure 2. Triple isotope data for variable sulfate chemostat experiments. The left y-axis 673 indicates ${ }^{33} \lambda$, again plotted against ${ }^{34} \boldsymbol{\varepsilon}$ for $D$. vulgaris (blue circles) and D. alaskensis (green 674 closed squares). The right $\mathrm{y}$-axis shows $\Delta^{33} \mathrm{~S}$, plotted against ${ }^{34} \boldsymbol{\varepsilon}$ for $D$. vulgaris (red open 675 circles) and D. alaskensis (red closed circles).

677 Figure 3. Comparison between our data (D. vulgaris in red and D. alaskensis in blue) and those 678 generated in a semi-continuous culture apparatus by Habicht et al. (2002, 2005) (in black 679 symbols), along with values from $D$. desulphuricans (green) from Harrison and Thode, (1958), 680 from closed-system experiments. Data from Habicht et al. (2002, 2005) include enrichment 681 (mixed) cultures from freshwater (diamonds) and marine (squares) environments, as well as pure 682 culture studies on the hyperthermophilic Arcahaea, Archaeoglobus fulgidis strain Z (triangles).

Figure 4: The operation of sulfite reduction by Dsr: sulfite and electrons are supplied to the enzyme DsrAB, which is complexed with DsrC. Partially reduced sulfur is removed by DsrC, 686 which cycles to membrane-bound DsrMKJOP where cellular energy is conserved. During this 687 cycle, reduced $\mathrm{S}$ is released as $\mathrm{H}_{2} \mathrm{~S}$.

Figure 5: The relationship between sulfate concentration, csSRR, and expressed isotope 690 fractionation. A) relationship between sulfate concentration and isotope fractionation for a 691 variety of sulfate reduction rates. The maximum fractionation at lowest csSRR approaches the 692 equilibrium isotope fractionation between sulfate and sulfide. Concentrations are expressed in 693 multiples of $K_{\mathrm{m}-\text { frac }}$. B) Relationship between maximum fractionation and csSRR, for a variety of 
694 sulfate concentrations. the $\mathrm{x}$-axis in (B) is equivalent to a vertical line intersecting the $\mathrm{x}$-axis in 695 (A). inset shows the relationship between the curves at different concentrations. This relationship 696 follows a Monod curve (A).

698 Figure 6: Four ecological regimes relevant to sulfur isotope fractionation. The $x$-axis 699 indicates increasing sulfate concentration while y-axis indicates increasing electron donor 700 concentration. In growth under sulfate limitation, electron donor is in excess and fractionation is 701 low. In growth under electron donor limitation, a large fractionation is expected, primarily as a 702 function of slow growth. Co-limitation of sulfate and electron donor is likely to produce a 703 complex physiological pattern that is not well understood. Nutrient or other growth limitation 704 (e.g. temperature) suggests that both sulfate and donor will be abundant (as is typical at the 705 beginning of batch growth experiments); isotope fractionations are expected to be intermediate in 706 magnitude. Boundaries between these regimes are not sharp, and are expected to relate to the 707 cellular affinity $\left(A_{s}\right)$ for these substrates. 







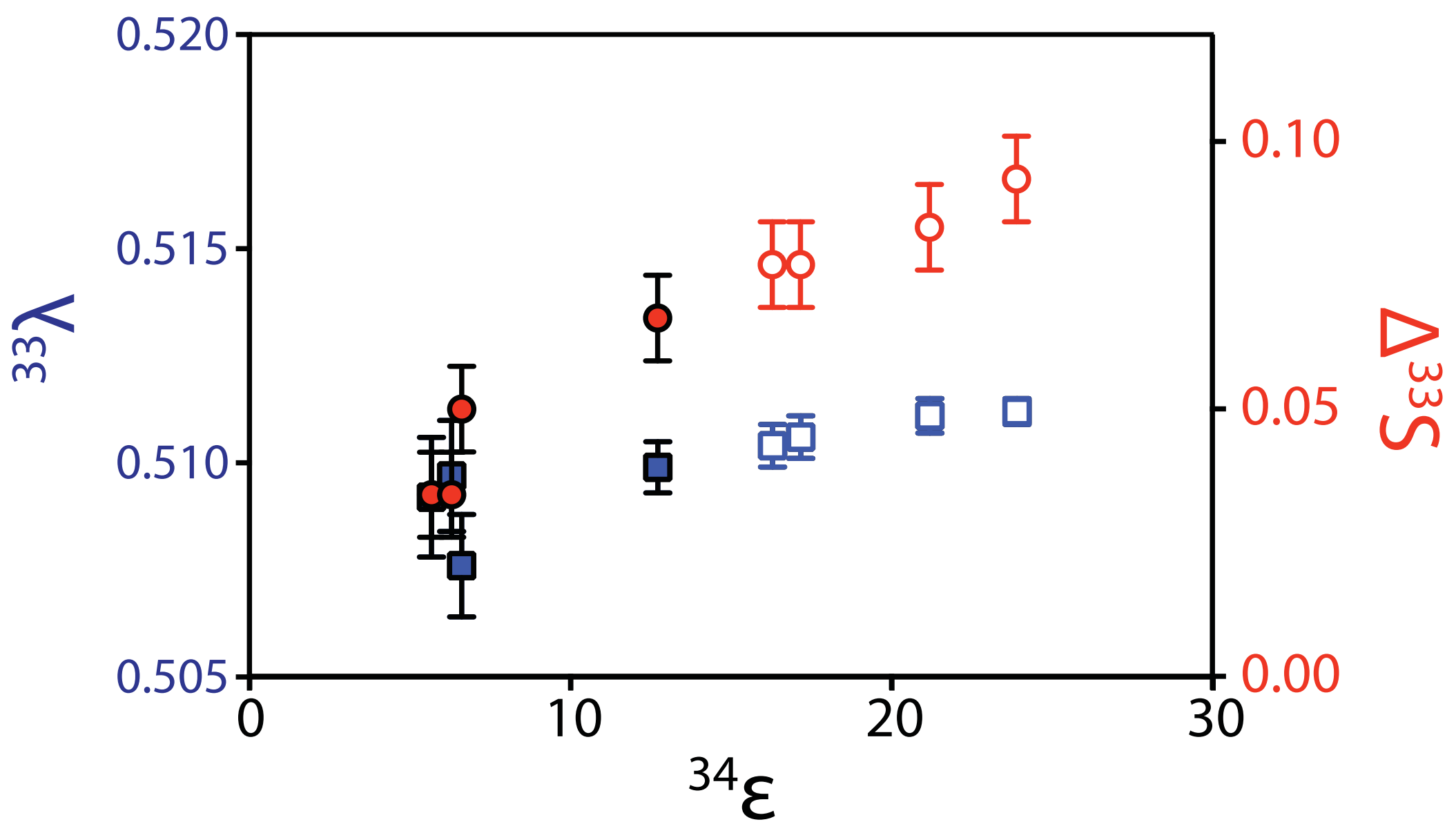




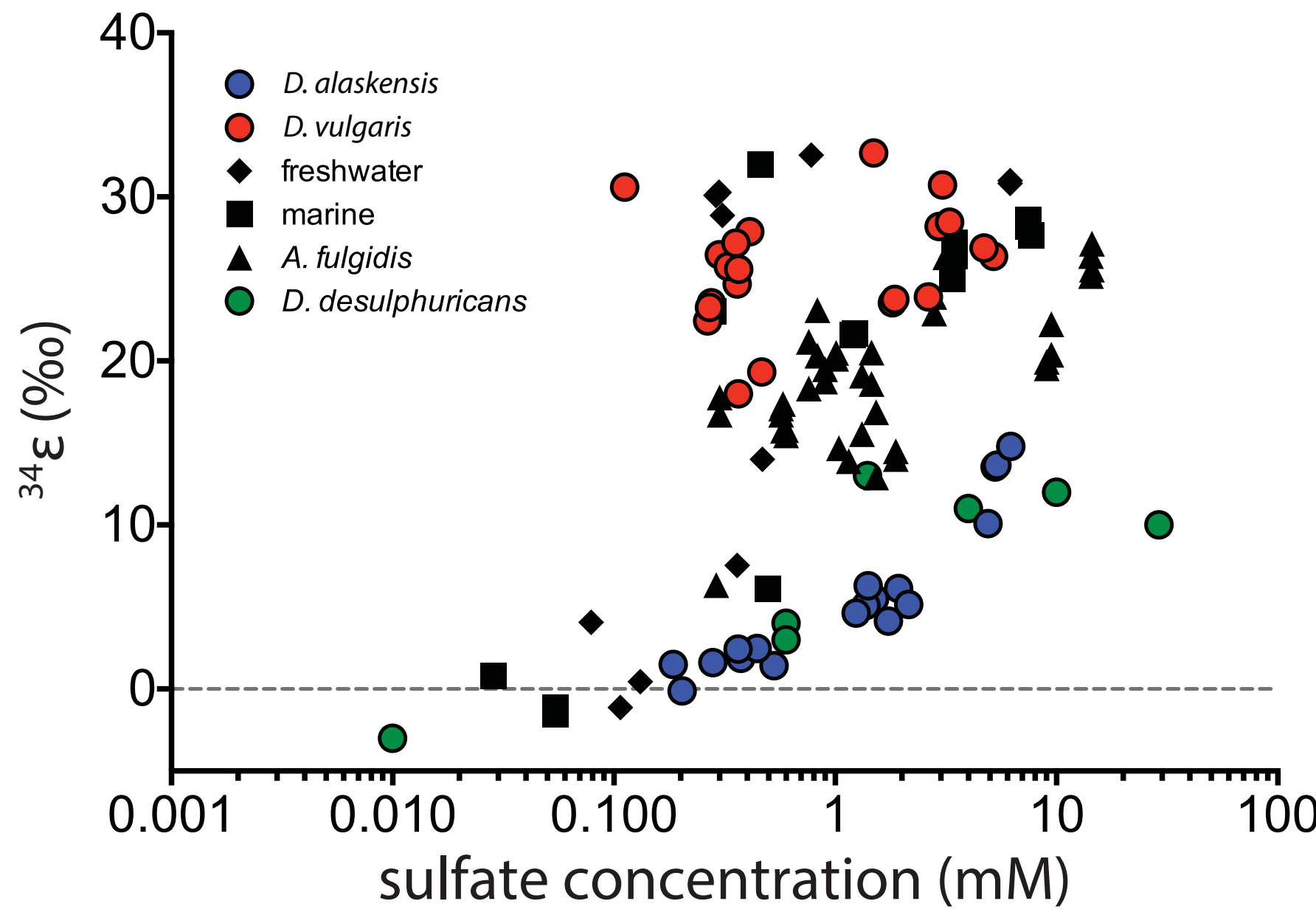

FIGURE 3 
$\mathrm{SO}_{3}{ }^{2-}$

O

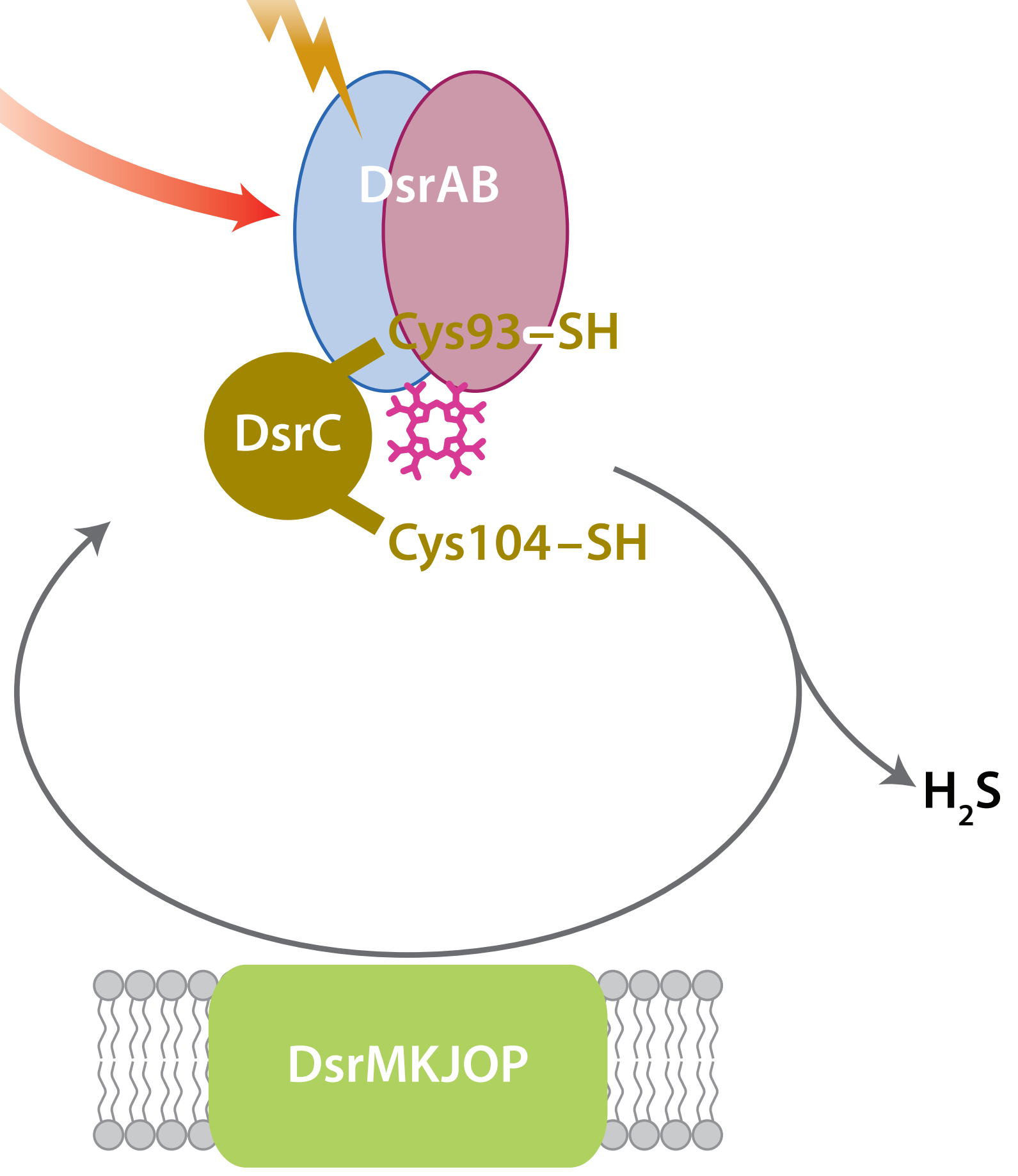


